Masahiro Arai · Tatsuya Sasaki ·

Satoshi Hirota - Hiroaki Ito •

Ning $\mathrm{Hu}$ - Marino Quaresimin

\title{
Mixed modes interlaminar fracture toughness of CFRP laminates toughened with CNF interlayer
}

Received: date / Accepted: date

\begin{abstract}
In the present paper, the influence of carbon nanofiber on interlaminar fracture toughness of CFRP investigated using MMB(Mixed Mode Bending) tests. Vapor grown carbon fiber VGCF and VGCF-S, and multi walled carbon nanotube MWNT-7 has been employed for the toughener of the interlayer on the CFRP laminates. In order to evaluate the fracture toughness and mixed mode ratio of it, double cantilever beam (DCB) tests, end notched fracture (ENF) tests and mixed mode bending (MMB) tests has been carried out. Boundary element analyses was applied to the CFRP model to compute the interlaminar fracture toughness, where extrapolation method was used to determine the fracture toughness and mixed mode ratio. The interlaminar fracture toughness and mixed mode ratio can be extrapolated by stress distribution at the vicinity of the crack tip of the CFRP laminate. It was found that the interlaminar fracture toughness of the CFRP laminates was improved inserting the interlayer made by carbon nanofiber especially in the region where shear mode deformation is dominant.
\end{abstract}

Keywords CFRP laminate · Fracture Toughness · Interlaminar Crack, Boundary Element Method, Interlayer

Masahiro Arai (Corresponding Author)

Shinshu University, 4-17-1, Wakasato, Nagano-shi, Nagano 380-8553, Japan

Tel.: +81-26-269-5161

E-mail: arai@shinshu-u.ac.jp

Tatsuya Sasaki, Satoshi Hirota, Hiroaki Ito

Shinshu University, 4-17-1, Wakasato, Nagano-shi, Nagano 380-8553, Japan

Ning $\mathrm{Hu}$

Chiba University, 1-33, Yayoi-cho, Inage-ku, Chiba-shi, Chiba, 263-8522, Japan

Marino Quaresimin

University of Padova, Stradella San Nicola 3, 36100 Vicenza, Italy 


\section{Introduction}

Over the past few decades, fiber reinforced plastics (FRP) has been developed as the foremost material for products in fields such as mechanical, electrical, architectural, and structural engineering. Carbon fiber reinforced plastic (CFRP) has especially attained a prominent position in use as structural materials for aeronautical and space engineering.

Application in this industry requires further improvement of the gravity to satisfy the demand for higher fuel efficiency. In the Boeing 787 project, the weight ratio was reported to have considerably improved owing to the adoption of CFRP for the main wing and fuselage[1]. Considering delamination growth in the view of fracture mechanics, interlaminar fracture toughness still plays an important role in damage propagation of CFRP.

Therefore, a number of experimental and analytical techniques have been proposed to estimate the fracture toughness for mode I[2-5], mode II $[6-8]$, mixed mode[9] with several combinations of carbon fiber and matrix resin.

Previous attempts to improve the interlaminar fracture toughness of CFRP laminates has shown various useful results. Namely, a certain level of toughening technique has already been achieved by inserting an interleaf (interlayer) between the CFRP Prepregs[10-13]. T800H/3900-2, with a heterogeneous interlayer consisting of fine thermo plastic particles, has shown high compressive strength after impact (CAI). In contrast, ionomer interleaved CFRP laminates have shown higher toughness under mode II deformations[14].

In recent years, carbon nanotubes and carbon nanofibers[15-17] have received a great deal of attention in the aeronautical, biological, electrical and mechanical sciences, and engineering fields. Due to the electrical conductivity superiority of the CNF, MWCNT or vapor grown carbon fiber 'VGCF' has established a strong presence in the storage battery field as the conductive filler.

In addition, carbon nanotubes and fibers have been applied as the toughening filler of the structural material for resin or metal based composites [18-20]. They are suitable for this application as they also have excellent mechanical properties such as elastic moduli, strength, fracture toughness, and flexibility compared with traditional carbon fiber based on polyacrylonitrile (PAN).

In recent years, inserting $\mathrm{CNF}$ filler and making $\mathrm{CNF} /$ resin interlayer between unidirectional CFRP prepregs, it was reported that the mode I and mode II interlaminar fracture toughness can be increased[21-23].

In the present study, interlaminar fracture toughness for mixed mode (opening and shearing modes) were investigated for carbon fiber (CF)/epoxy laminates toughened with a carbon nanofiber/epoxy interlayer. Vapor grown carbon fiber VGCF, VGCF-S and MWNT-7 were chosen as the reinforcement for the interlayer between the prepregs in the CFRP laminates[21].

To illustrate the effect of the interlayer on the fracture toughness of the laminates, several types of carbon fiber reinforced plastics/carbon nanofiber (CFRP/CNF) hybrid laminates were fabricated. Each laminate was composed of unidirectional carbon/epoxy prepregs with carbon nanofiber varying the interlayer thickness. Mixed modes interlaminar fracture toughness was 


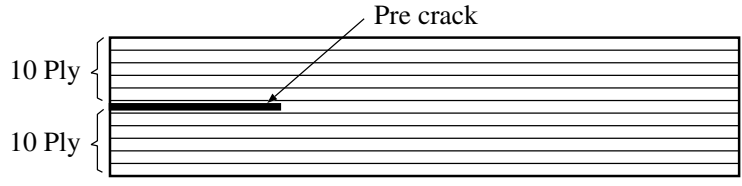

(A) Base Laminate (CFRP)

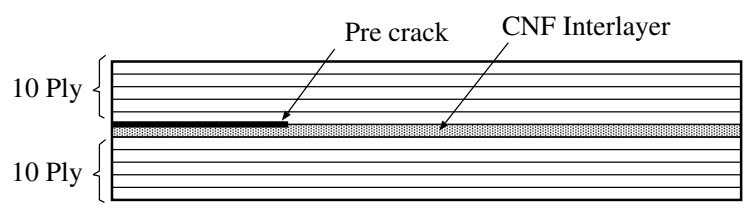

(B) CFRP Toughened with CNF Interlayer

Fig. 1 Unidirectional CFRP specimen for the fracture toughness test.

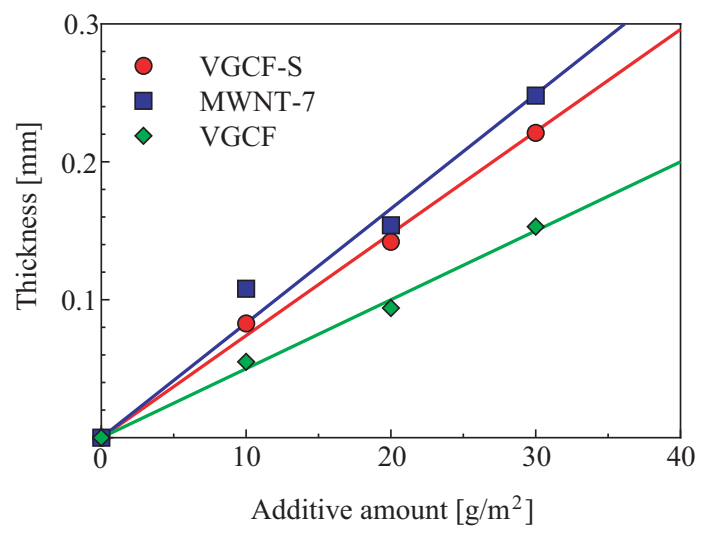

Fig. 2 Relation between thickness and area density of CNF ingterlayer.

evaluated by mixed mode bending (MMB) test[24][25]. The mixed modes interlaminar fracture toughness was evaluated by numerical analysis based on a boundary element method.

As a result, it was confirmed that the interlaminar fracture toughness for CFRP laminate with a CNF interlayer is higher than that of base CFRP laminates. Especially, the fracture toughness of the CFRP/CNF laminate reaches 3.6 times of those derived by base CFRP laminates in the area where the shearing deformation becomes predominant. It was found that the recommended thickness CNF interlayer thickness is between 100 to $150 \mu \mathrm{m}$.

\section{CFRP Specimens}

In the present study, unidirectional Carbon/Epoxy prepreg (P3051S-22, TORAY) has been used to make unidirectional CFRP laminates. Unidirec- 
Table 1 Dimensions of CFRP specimen.

\begin{tabular}{ll}
\hline Thickness & $4.5 \mathrm{~mm}$ \\
\hline Length & $115 \mathrm{~mm}$ \\
\hline Width & $20 \mathrm{~mm}$ \\
\hline Crack length & $25 \mathrm{~mm}$ \\
\hline
\end{tabular}

Table 2 Young's moduli and Poisson's ratio of unidirectional CFRP laminate.

\begin{tabular}{cc}
\hline $0^{\circ}$ Young's Modulus $E_{L}[\mathrm{GPa}]$ & 106.6 \\
\hline $90^{\circ}$ Young's Modulus $E_{T}[\mathrm{GPa}]$ & 8.0 \\
\hline Shear Modulus $G_{L T}[\mathrm{GPa}]$ & 3.37 \\
\hline Shear Modulus $G_{T T}[\mathrm{GPa}]$ & 2.60 \\
\hline Poisson Ratio $\left[\nu_{L T}\right]$ & 0.30 \\
\hline Poisson Ratio $\left[\nu_{T T}\right]$ & 0.54 \\
\hline Poisson Ratio $\left[\nu_{T L}\right]$ & 0.0225 \\
\hline
\end{tabular}

Table 3 Young's modulus of CNF interlayer.

\begin{tabular}{ll}
\hline VGCF & $5.52 \mathrm{GPa}$ \\
\hline VGCF-S & $4.47 \mathrm{GPa}$ \\
\hline MWNT-7 & $4.55 \mathrm{GPa}$ \\
\hline
\end{tabular}

tional CFRP beam specimens were composed of 20 prepreg layers. An artificial crack was inserted in the middle plain of CFRP beam using polyimide film of $30 \mu \mathrm{m}$ thickness as shown in Fig. 1(A). The CFRP specimens were made by autoclave in our laboratory. Carbon nanofiber (CNF) interlayer has been employed to reinforce the interlaminar of the CFRP laminates. In this specimens, CNF interlayer was inserted between 10th and 11th prepreg of the CFRP laminates as shown in Fig. 1(B). The precrack was inserted between $0^{\circ}$ prepreg layer and $\mathrm{CNF}$ interlayer. The dimensions of the CFRP beam sepecimens for the fracture toughness tests are shown in Table 1. Young's moduli and Poisson's ratios of the unidirectional P3051S-22 CFRP laminate are shown in Table 2.

VGCF, VGCF-S(Showa Denko K. K.) and MWNT-7(Hodogaya Chemical Co., LTD.) are kinds of multi-walled carbon nanotubes. In the present study, they were used for the reinforcement of the CFRP laminates. Powder of the CNF was inserted between prepregs of the CFRP specimens with an area density of 10,20 and $30 \mathrm{~g} / \mathrm{m}^{2}$ using a sifter[23]. An interlayer from $50 \mu \mathrm{m}$ to $250 \mu \mathrm{m}$ mean thickness was naturally formed by the fusion of CNF and epoxy resin leaking into the interlayer during the production process of the specimens. Relation between the area density and the thickness of interlayer is shown in Fig.2. Young's moduli of the CNF interlayer are shown in Table 3. They were evaluated by Vickers Hardness (VH) using a Micro Vickers testing machine (DUH-201, Shimadzu Co.). 


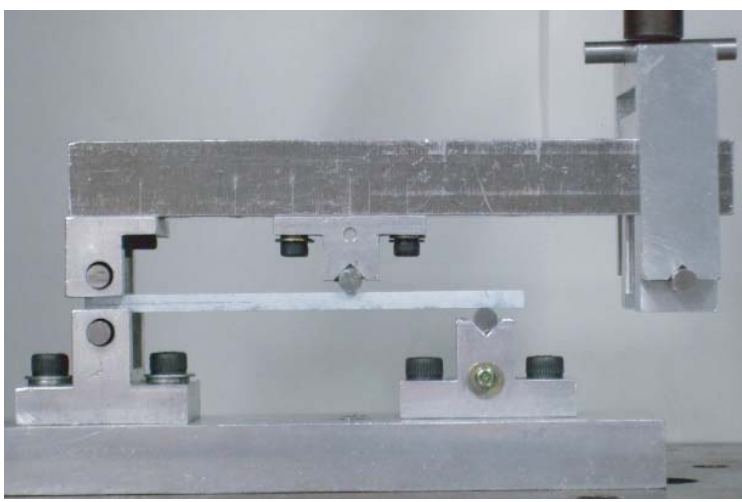

Fig. 3 Mixed modes bending (MMB) test for CFRP laminates.
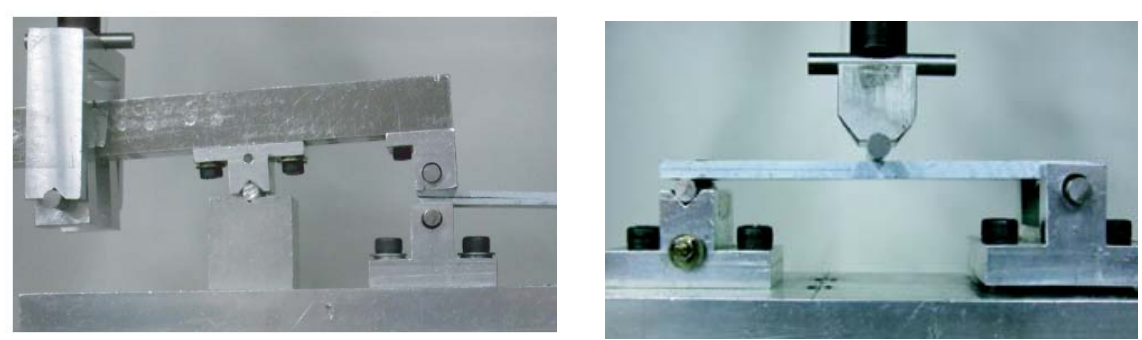

Fig. 4 Left:Double cantilever beam (DCB) test, Right: End notched flexure test.

\section{Fracture Toughness Tests for CFRP specimens}

The authors group already applied mixed mode bending (MMB) test to evaluate interlaminar fracture toughness of CFRP laminates[27]. Using MMB tests the mixed mode ratio (for the opening mode and shearing mode) can be controlled with wide range. In the present study the MMB equipment as shown in Fig. 3 has been used. The vertical load was applied on the cantilever of the equipment by the universal material testing machine (SHIMADZU AGE-100kNE). In case that the opening mode and shearing mode were predominant, the DCB and ENF tests were executed additionally (Fig.4).

\section{Boundary Element Analysis}

In the present study, the boundary element method has been applied for 2dimensional analyses of CFRP laminates[28]. In boundary element method, the following integral equation, which is the relational equation between the displacement $u_{j}(\mathrm{Q})$ and traction $t_{j}(\mathrm{Q})$ on the boundary $\Gamma$, is employed.

$$
\frac{1}{2} u_{i}(\mathrm{P})+\int_{\Gamma} T_{i j}(\mathrm{P}, \mathrm{Q}) u_{j}(\mathrm{Q}) d \Gamma=\int_{\Gamma} U_{i j}(\mathrm{P}, \mathrm{Q}) t_{j}(\mathrm{Q}) d \Gamma \quad(\mathrm{P} \in \Gamma)
$$




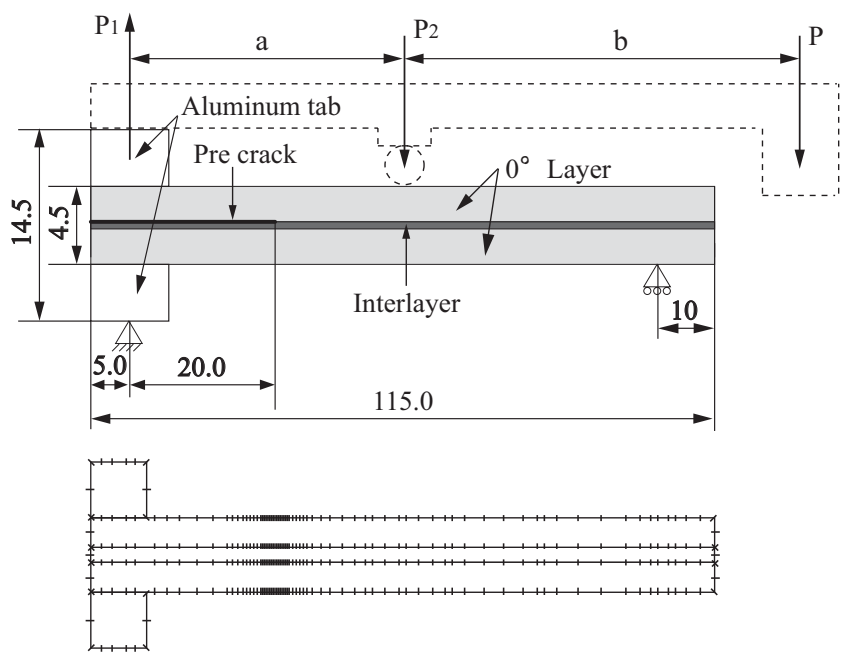

Fig. 5 Analytical model for boundary element method.

where $U_{i j}$ is a green function (fundamental solution) for the 2-dimensional anisotropic solid body. $T_{i j}$ is a traction component on $\mathrm{Q}$ derived from $U_{i j}$. Discretizing the boundary integral equation (1) using boundary-line element, and applying the boundary conditions, we obtain the numerical solutions of displacements and tractions on the boundary.

The analytical model for BEM analysis is shown in Fig. 5. The total domain was divided into 5 domains ( 2 domain for CFRP laminates, 1 domain for $\mathrm{CNF}$ interlayer and 2 domain for aluminum tab). Non-conforming quadratic boundary element was used for the discretization of the boundary. On the other hand, the boundary profile of the CFRP beam was approximated traditional quadratic boundary element. The number of element were 472 for the base CFRP laminates and 694 for CFRP toughened with CNF interlayer.

\section{Evaluation of Fracture Toughness of CFRP}

To evaluate the interlaminar fracture toughness of CFRP laminates toughened by $\mathrm{CNF}$ interlayer $(\mathrm{CFRP} / \mathrm{CNF})$, the definition of the interlaminar fracture toughness of CFRP laminate has been introduced. The delamination between the prepreg layer and CNF interlayer should be treat as a crack between dissimilar anisotropic material $[29,30]$. Therefore, the stress field near the crack tip becomes mixed mode state derived by complex stress intensity factor $K_{1}$ and $K_{2}$ [31]. In the present study, the definition of singular stress field at the vicinity of the crack tip is expressed by the definition of Yuuki[32, 33 which is modified formula of the Suo's definition[31].

If the normal direction of the anisotropy is parallel to the axis $x_{i}\left(\phi_{1}\right.$ and $\phi_{2}=0^{\circ}$ or $90^{\circ}$ ) as shown in Fig. 6 , the tensile stress $\sigma_{y}$ and shear stress $\tau_{x y}$ 


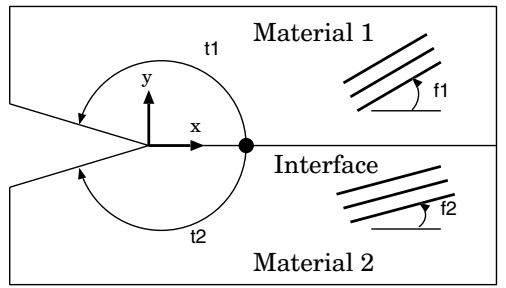

Fig. 6 Dissimilar anisotropic interface crack.

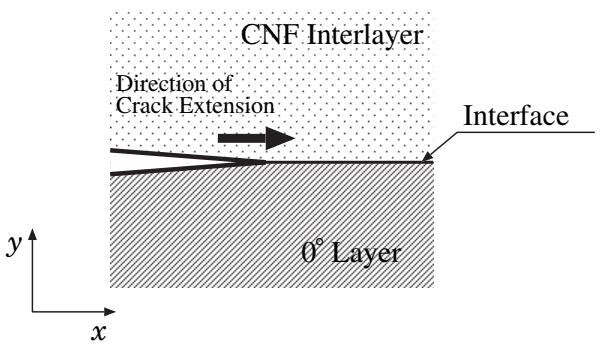

Fig. 7 Direction of the crack propagation and the stacking order of the CNF interlayer and $0^{\circ}$ prepreg layer for the definition of the complex stress intensity factor $K_{1}$ and $K_{2}$.

at the vicinity of the crack tip can be expressed as the following equations.

$$
\sigma_{y}+i \sqrt{\frac{H_{11}}{H_{22}}} \tau_{x y}=\frac{K_{1}+i \sqrt{\frac{H_{11}}{H_{22}}} K_{2}}{\sqrt{2 \pi r}}\left(\frac{r}{l}\right)^{i \varepsilon} .
$$

A energy release rate $G$ can be derived as

$$
G=\frac{H_{22} K_{1}^{2}+H_{11} K_{2}^{2}}{4 \cosh ^{2}(\varepsilon \pi)},
$$

where $H_{11}, H_{22}$ and $\varepsilon$ can be calculated by elastic moduli of the anisotropic materials of the laminate, $r$ denotes the distance from the crack tip, $i$ is a imaginary unit, respectively. $K_{1}$ and $K_{2}$ are complex stress intensity factors for the dissimilar anisotropic interface crack. $K_{1}$ is for the opening mode $K_{2}$ is for the shearing mode, respectively. The characteristic length $l$ is set to be the initial crack length $(25 \mathrm{~mm})$.

Rewriting the Eq. (2), the energy release rate $G$ can be written by

$$
G=\frac{H_{22} K_{i}^{2}}{4 \cosh ^{2}(\varepsilon \pi)}
$$

where $K_{i}=\sqrt{{K_{1}{ }^{2}+S^{2} K_{2}^{2}}^{2}}, S=\sqrt{H_{11} / H_{22}}$.

Parameter $K_{i}$ can be determined by extrapolation of the singular stress field near the crack tip by the following equation.

$$
K_{i}=\lim _{r \rightarrow 0} \sqrt{2 \pi r\left(\sigma_{y}^{2}+S^{2} \tau_{x y}^{2}\right)} .
$$


Mode ratio $K_{2} / K_{1}$ for the opening and the shearing mode can be determined by the following extrapolation equation.

$$
\frac{K_{2}}{K_{1}}=\lim _{r \rightarrow 0} \frac{1}{S} \frac{S \frac{\tau_{x y}}{\sigma_{y}}-\tan Q}{1+S \frac{\tau_{x y}}{\sigma_{y}} \tan Q}, \quad Q=\varepsilon \ln (r / l) .
$$

In the following discussion, the "phase angle" has been employed to discuss the effect of mixed-mode ratio instead of the mode ratio $K_{2} / K_{1}$.

$$
\theta=\tan ^{-1} \frac{K_{2}}{K_{1}}
$$

Note that the value of a phase angle is dependent on the characteristic length $l$. Namely if $l$ is changed, the phase angle $\tan ^{-1}\left(K_{2} / K_{1}\right)$ will also change. About this problem, it is necessary to argue using a fixed value of the characteristic length $l$. It is because the generality about a phase angle $\theta$ will be lost if $l$ is changed. As long as the fixed value $l$ is used, a unific argument can be attained to discuss the criterion of anisotropic dissimilar crack in the CFRP laminates.

When the complex stress intensity factor $K_{1}$ and $K_{2}$ is employed, it is necessary to define the direction of the crack propagation and the stacking order of the laminates. In the present study the crack extension and the stacking order of the prepreg $0^{\circ}$ layer and CNF interlayer has been defined as shown in Fig. 7.

\section{Experimental Results}

The relationships between applied load and load point displacement obtained by MMB fracture toughness test are shown in Fig. 8, Fig. 9, Fig. 10 for CFRP/VGCF, CFRP/VGCF-S and CFRP/MWNT-7 specimens. Moreover, the same results obtained by ENF tests are shown in Fig. 11, Fig. 12 and Fig. 13, respectively. It is shown that the load-displacement relations for the laminates appear to be nearly linear up to the maximum point $\left(P_{\max }\right)$. From the maximum load $P_{\max }$, the fracture toughness (critical value of the energy release rate) can be calculated by Eqs (4) and (5), the phase angle $\theta$ can be given by Eqs (6) and (7) extrapolating the singular stress field near the crack tip.

Relations between phase angle $\theta$ and intarlaminar fracture toughness $G_{c}$ for the CFRP/VGCF laminates are shown in Fig. 14. In this figure, the fracture toughness of base CFRP laminates are also indicated. The area density of CNF inserted between the prepregs was controlled as 10,20 and $30 \mathrm{~g} / \mathrm{m}^{2}$. Figure 15 and Fig. 16 show the similar results to CFRP/VGCF-S and CFRP/MWNT-7 laminates, respectively.

Since the horizontal axis of these figures is a phase angle $\theta=\tan ^{-1} K_{2} / K_{1}$, the opening mode becomes predominant at the vicinity of $\theta=0$, on the other hand the shearing mode becomes predominant at the vicinity of $\theta=90$. As shown in these figures, the interlaminar fracture toughness of CFRP and 
CFRP/CNF laminates increase as the shearing mode becomes predominant, and the CFRP/CNF laminate indicates the tendency stronger than the base CFRP laminate.

In the area in which opening mode becomes predominant $\left(\theta \simeq 0^{\circ}\right)$, the fracture toughness of CFRP with CNF interlayer becomes from 1.3 to 2.3 times of that of base CFRP laminate. On the other hand, in the area in which shearing mode becomes predominant $\left(\theta \simeq 90^{\circ}\right)$, the fracture toughness of $\mathrm{CFRP} / \mathrm{CNF}$ reaches 3.6 times of that of base laminate. Therefore, it is shown that CNF interlayer has the effect of improving the fracture toughness when the shearing mode is predominant.

In the past research[21], it was found that the adaptive quantity of CNF interlayer was $20 \mathrm{~g} / \mathrm{m}^{2}$ in the Mode II interlaminar fracture toughness testing. It was found that the recommended range of CNF interlayer thickness is between 100 to $150 \mu \mathrm{m}$ judging from the present results for VGCF, VGCF$\mathrm{S}$ and MWNT-7 interlayers. However, the influence of the quantity of CNF filler was not confirmed enough in the present results. However, this tendency is reversed in the mixed mode area. In the area about $\theta=70^{\circ}$, the fracture toughness of VGCF interlayer is slightly superior than that of other CNF.

As shown in the Figs 14, 15 and 16, a large difference is not found in these three kinds CNF interlayers about the fracture toughness of opening mode. In the area in which the shearing mode is predominant, MWNT-7 interlayer gives the highest fracture toughness in these CNFs. From these results, it is found that $\mathrm{CNF}$ of smaller diameter is more effective to improve the fracture toughness in a shear mode predominant area.

To verify this reason, the fracture surfaces of the laminates were observed with the scanning electron microscope (SEM). Fracture surfaces of the CFRP specimens with VGCF, VGCF-S, MWNT-7 interlayer and base CFRP laminate obtained with phase angle $67^{\circ} \leq \theta \leq 70^{\circ}$ are shown in Fig. 17 In the Fig. 17. the prepreg side of the fracture surfaces was observed in each specimens. On the fracture surfaces the hackle marking with $20-80 \mu \mathrm{m}$ pitch are found which are typical aspects of the fracture delamination surfaces produced by shearing fracture extension. Although it is confirmed that marking in the base CFRP laminate is the smallest (about $20 \mu \mathrm{m}$ pitch), there is no clear difference in the size and the shape of hackle marking in the three kinds of CFRP specimens toughened with CNF interlayers

Figure 18 is the SEM images on the CNF interlayer sides observed by high magnification. The VGCF-S and MWNT-7 are exposed on the fracture surface, and the nanofiber are pulled out from matrix Epoxy resin as shown in Fig. 18(b) and (c). On the other hand, the exposure of the VGCF fiber on the fracture surface is comparatively few (see Fig. 18(a)). Moreover, cutting sign of the nanofiber is found on the fracture surface in VGCF case. It seems that the difference of the fracture surface described above is main reason that the VGCF interlayer indicates the higher fracture toughness than the other CNF. 


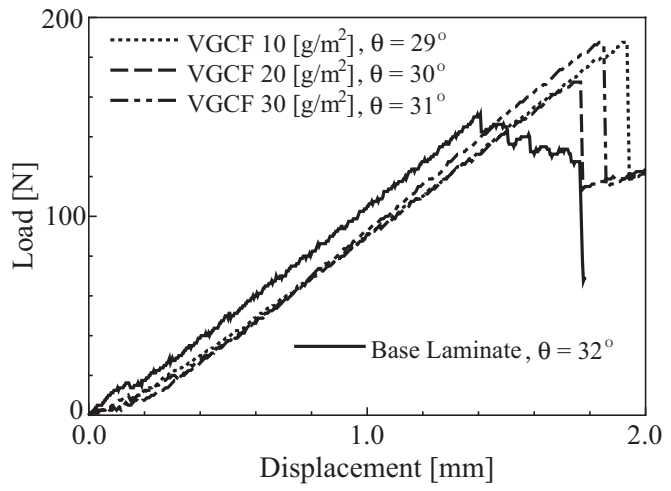

Fig. 8 Load v.s. displacement curves in typical specimens of CFRP/VGCF laminates obtained by MMB tests.

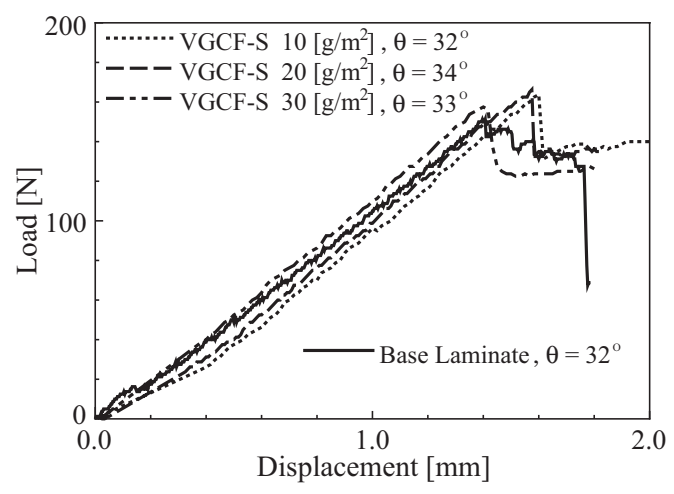

Fig. 9 Load v.s. displacement curves in typical specimens of CFRP/VGCF-S laminates obtained by MMB tests.

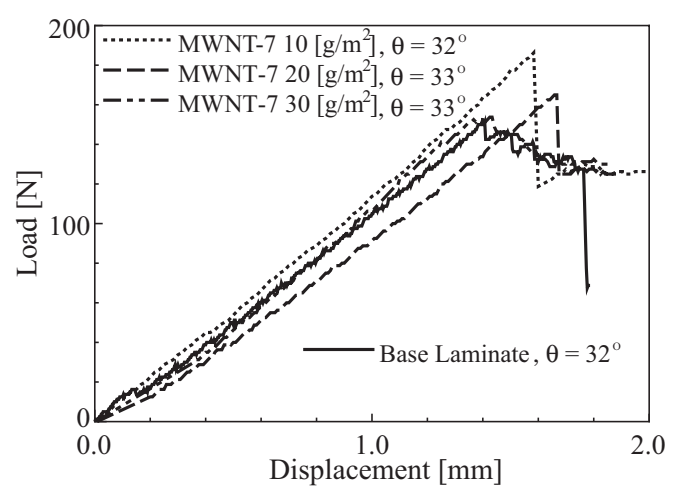

Fig. 10 Load v.s. displacement curves in typical specimens of CFRP/MWNT-7 laminates obtained by MMB tests. 


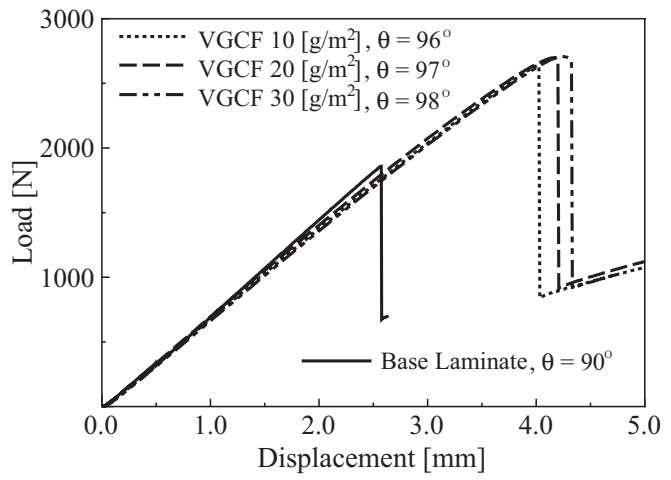

Fig. 11 Load v.s. displacement curves in typical specimens of CFRP/VGCF laminates obtained by ENF tests.

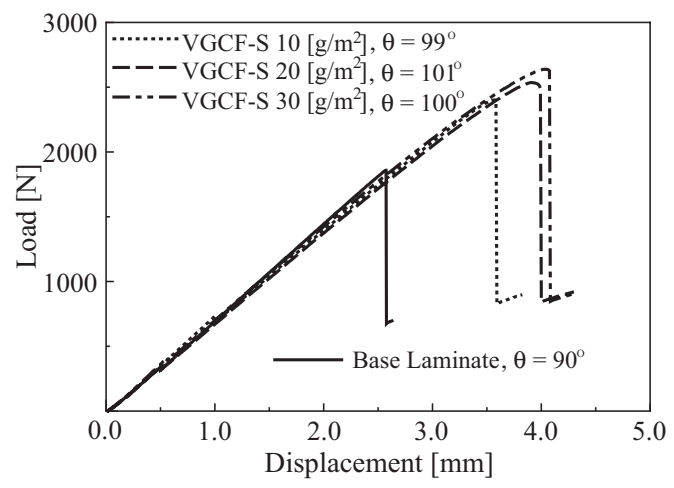

Fig. 12 Load v.s. displacement curves in typical specimens of CFRP/VGCF-S laminates obtained by ENF tests.

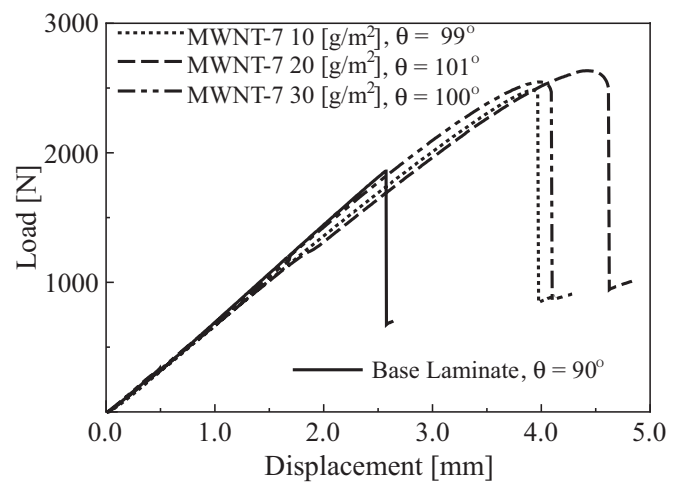

Fig. 13 Load v.s. displacement curves in typical specimens of CFRP/MWNT-7 laminates obtained by ENF tests. 


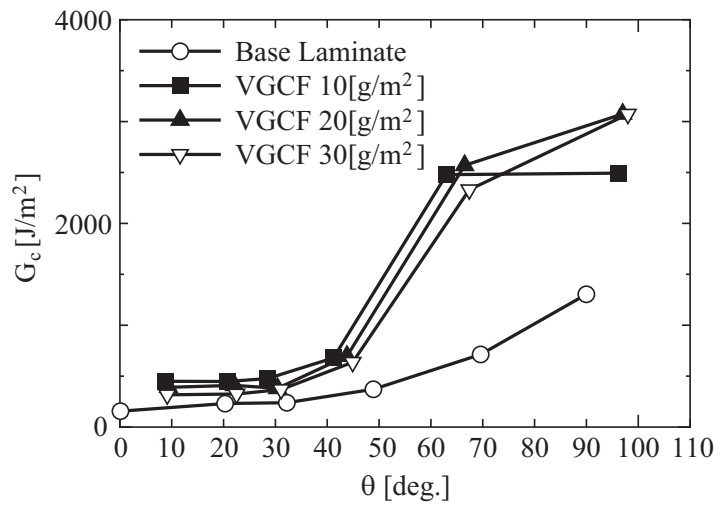

Fig. 14 Relation between phase angle $\theta$ and interlaminar fracture toughness $G_{c}$ (VGCF interlayer).

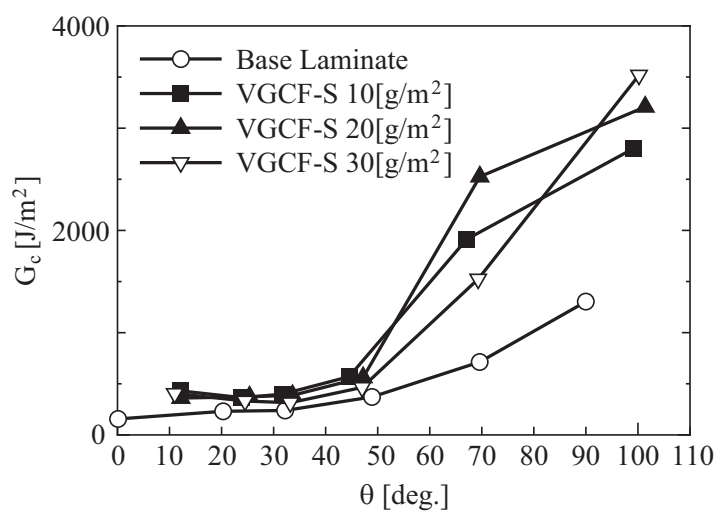

Fig. 15 Relation between phase angle $\theta$ and interlaminar fracture toughness $G_{c}$ (VGCF-S interlayer).

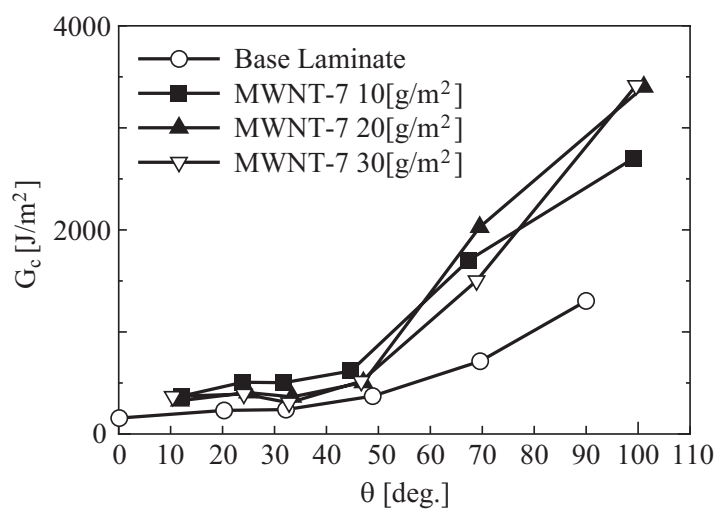

Fig. 16 Relation between phase angle $\theta$ and interlaminar fracture toughness $G_{c}$ (MWNT-7 interlayer). 


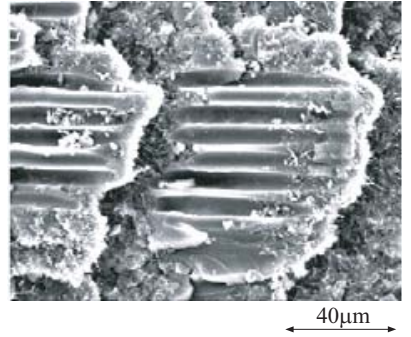

(a) $\operatorname{VGCF}\left(\theta=67^{\circ}\right)$

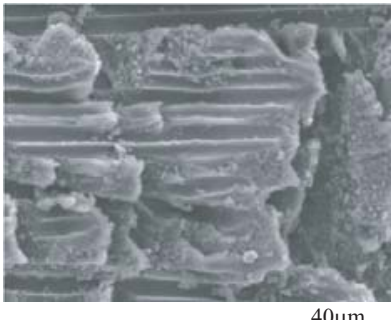

(c) $\operatorname{MWNT}-7\left(\theta=69^{\circ}\right)$

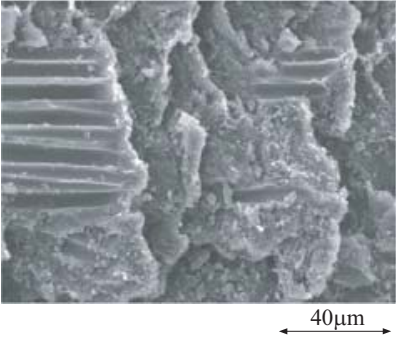

(b) VGCF-S $\left(\theta=69^{\circ}\right)$

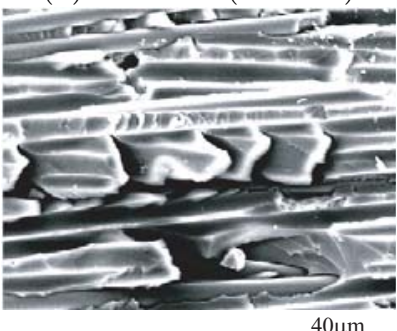

(d) Base $\operatorname{CFRP}\left(\theta=70^{\circ}\right)$

Fig. 17 Fracture surfaces of CFRP/CNF laminates observed by scanning electron microscope (low magnification, prepreg side).

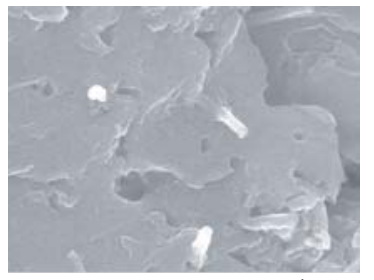

(a) $\operatorname{VGCF}\left(\theta=\frac{1 \mu \mathrm{m}}{\left.67^{\circ}\right)}\right.$

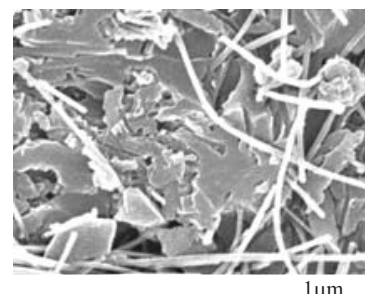

(b) VGCF-S $\left(\theta=\longdiv { 6 9 ^ { \circ } ) }\right.$

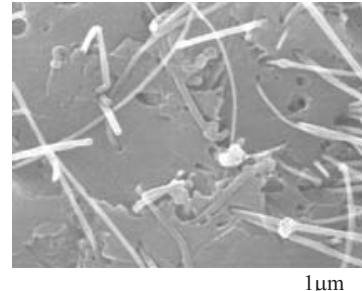

(c) $\operatorname{MWNT-7}\left(\theta=\overleftrightarrow{\left.69^{\circ}\right)}\right.$

Fig. 18 Fracture surfaces of CFRP/CNF laminates observed by scanning electron microscope (high magnification, CNF interlayer side).

\section{Conclusions}

Interlaminar fracture toughness for mixed mode deformation were investigated for CFRP laminates toughened with CNF interlayer. VGCF, VGCF-S and MWNT-7 were employed as the stiffeners for the interlayers between the unidirectional CFRP prepregs of the specimens. Mixed mode bending, double cantilever beam and end notch flexure tests were applied to the CFRP/CNF composites to evaluate the interlaminar fracture toughness with several mixed mode ratio. Boundary element analyses was applied to the CFRP beam specimen to compute the interlaminar fracture toughness.

For mixed mode deformation, interlaminar fracture toughness for CFRP/CNF laminates has the greatest value with $20 \mathrm{~g} / \mathrm{m}^{2} \mathrm{CNF}$ area density 
(about $100-150 \mu \mathrm{m}$ thickness). In the area in which opening mode becomes predominant, the fracture toughness of CFRP with CNF interlayer became from 1.3 to 2.3 times of that of base CFRP laminate without the interlayer. On the other hand, in the area in which shearing mode becomes predominant, the fracture toughness of CFRP/CNF reached 3.6 times of that of base laminate.

Observation of the SEM image on the fracture surfaces shows that the intensity of the fracture toughness of the mixed mode state is related to the hackle marking and the exposure state of the CNF on the fracture surface.

However, it still has a question why a relative thick interlayer of 100-150 micron is required to achieve the optimum toughening. It needs to perform still more detailed examination to clarify this problem in the future work.

\section{Acknowledgment}

This research was supported by Program for Fostering Regional Innovation in Nagano, granted by MEXT, Japan.

\section{References}

1. Glover,B.M., History of development of commercial aircraft and 7E7 dreamliner. Aviation Engineering, 2004, 592: 16-21.

2. Kageyama,K., Kobayashi,T., Yanagisawa,N., Kikuchi,M., Miyamoto,H., Mode I Interlaminar Fracture Mechanics of Unidirectionally Reinforced Carbon/Nylon Laminates. Transactions of the Japan Society of Mechanical Engineers (in Japanese), 1987, 53(496): 2386-2393.

3. Gillespie,Jr.J.W., Carlsson,L.A., Smiley,A.J., Rate-Dependent Mode I Interlaminar Crack Growth Mechanisms in Graphite/Epoxy and Graphite PEEK. Composite Science and Technology, 1987, 28: 1-15.

4. Mall,S., Law,G.E., Katouzian,M., Loading Rate Effect on Interlaminar Fracture Toughness of Thermoplastic Composite. Journal of Composite Materials, 1987, 21-June: 569-579.

5. Shi,Y.B., Hull,D., Fracture of Delaminated Unidirectional Composite Beams. Journal of Composite Materials, 1992, 26(15): 2172-2195.

6. Wilkins,D.J., Eisenmann,J.R., Camin,R.A., Margolis,W.S., Benson,R.A., Characterizing Delamination Growth in Graphite-Epoxy. Damage in Composite Materials, Ed. Reifsnider KL, American Society for Testing and Materials, ASTM STP 775, 1982: 168-183.

7. Carlsson,L.A., Gillepie,J.W., Trethewey,B.R., Mode II Interlaminar Fracture of Graphite/Epoxy and Graphite/PEEK. Journal of Reinforced Plastics and Composites, 1986, 5-July: 170-187.

8. Maikuma,H., Gillespie,J.W., Wilkins,D.J., Mode II Interlaminar Fracture of the Center Notched Flexural Specimen under Impact Loading. Journal of Composite Materials, 1990, 24-February: 124-149.

9. Valisetty,R.R., Chamis,C.C., Sublaminate- or Ply-Level Analysis of Composite and Strain Energy Release Rates of End-Noch and Mixed-Mode Fracture Specimens. Composite Materials: Testing and Design(Eighth Conference), ASTM STP 9u72, Ed., Whitcomb, J.D., American Society for Testing Materials, 1988: $41-56$.

10. Sela.N., Ishiai,O., Banks-Sills,L., The effect of adhesive thickness on interlaminar fracture toughness of interleaved laminates specimens. Composite, 1989, 20(3): 257-264.

11. Singh,S., Partridge,I.K., Mixed mode fracture in and interleaved carbonfiber/epoxy composite. Composite Science and Technology, 1995, 55: 319-327. 
12. Hojo,M., Matsuda,S., Tanaka,M., Ochiai,S., Murakami,A., Mode I delamination fatigue properties of interlayer-toughned CF/epoxy laminates. Composites Science and Technology, 2006, 66: 665-675.

13. Hojo,M., Ando,T., Tanaka,M., Adachi,T., Ochiai,S., Endo,Y., Modes I and II interlaminar fracture toughness and fatigue delamination of $\mathrm{CF} /$ epoxy laminates with self-same epoxy interleaf. International Journal of Fatigue, 2006, 28(10): 1154-1165

14. Matsuda,S., Hojo,M., Ochiai,S., Mesoscopic fracture mechanism of interleaftoughned CFRP. JSME International Journal (Series A), 1997, 40(4): 423-429.

15. Oberlin,A., Endo,M., Koyama,T., Filamentous growth of carbon through benzene decomposition. Journal of Crystal Growth, 1976, 32: 335-349.

16. Endo,M., Grow carbon fibers in the vapor phase. CHEMTECH, 1988, September: $568-576$.

17. Iijima,S., Helical microtubules of graphitic carbon, Nature,1991, 354: 56-58.

18. Sandler,J., Werner,P., Shafer,M.S.P., Demchuk,V., Altstadt,V., Carbonnanofibre-reinforced poly (ether ether ketone) composite. Composites Part A, 2002, 33: 1033-1039.

19. Yamamoto,G., Hashida,T., Omori,M., Kimura,H., Reinforcement of Alumina with Surface Modified Carbon Nanotube, Materials Science Forum, 2010, 631632: 231-236.

20. Hu.N., Masuda.Z., Yamamoto,G., Fukunaga,H., Hashida,T., Qiu,J., Effect of fabrication process on electrical properties of polymer/multi-wall carbon nanotube nanocomposites, Composites Part A, 2008, 39: 893-903.

21. Arai,M., Noro,Y., Sugimoto,K., Endo,M., Mode I and mode II interlaminar fracture toughness of CFRP laminates toughened by carbon nanofiber interlayer, Journal of Composites Science and Technology, 2008, 68(2): 516-525.

22. Yokozeki,T., Iwahori,Y., Ishibashi,M., Yanagisawa,T., Imai,K., Arai,M., Takahashi,T., Enomoto,K., Fracture toughness improvement of CFRP laminates by dispersion of cup-stacked carbon nanotubes, journal of composites science and technology, 2009, 69(14): 2268-2273.

23. Li,Y., Hori,N., Arai,M., Hu,N., Liu,Y., Fukunaga,H., Improvement of interlaminar mehcanical properties of CFRP laminates using VGCF, Composites Part A, 2009, 40: 2004-2012.

24. Reeder,J.R., Crews Jr.J.H., Mixed-mode bending method for delamination testing, AIAA Journal, 1990, 28(7): 1270-1276.

25. Reeder,J.R., Crews Jr.,J.H., Redesign of the mixed-mode bending delamination test to reduce non-linear effects, Journal of Composites Technology and Research, 1992, 14: 12-19.

26. Chen,J.H., Sernow,R., Schulz,E., Hinrichsen,G., Composities Part A, 1999, 30: 871-877.

27. Arai,M., Takagi,T., Kuwahara,T., Adachi,T., Evaluation of interlaminer fracture toughness of cross-ply CFRP laminates using mixed mode bending test, Transactions of the JSME Series A, 2004, 70(698): 1356-1363 (in Japanese).

28. Arai,M., Sumida,T., Shimizu,M., Effect of Residual Stress on Interlaminar Fracture Toughness of CFRP Laminates, Journal of Thermal Stress, 2007, 30: 1099-1116.

29. Dunders,J., Edge-bonded dissimilar orthogonal elastic wedges under normal and shear loading, Journal of Applied Mechanics, 1969, 36: 650-652.

30. Dunders,J., Effects of elastic constants on stress in a composite under plane deformation, Journal of Composite Material, 1967, 1(4): 310-322.

31. Suo.Z., Singularities, Interface and cracks in dissimilar anisotropic media, Proceedings of the Royal Society of London Series A, 1990, 427: 331-358

32. Yuuki,R., Jinquan,X., Stress intensity factors for the interface crack between dissimilar orthotropic materials, Transactions of the JSME Series A, 1991, 57(539): 1542-1549 (in Japanese).

33. Cho,S.B., Lee,K.R., Choy,Y.S., Yuuki,R., Determination of stress intensity factors and boundary element analysis for interface cracks in dissimilar anisotropic materials, Engineering Fracture Mechanics, 1992, 43(4): 603-614. 